\title{
Aspects of Greek Teachers Concerning Teaching Within Co-educational Classes: An Exploratory Approach to Elementary School
}

\author{
Maria Sakellariou, Panagiota Strati \& Polyxeni Mitsi \\ University of Ioannina, Department of Pre-School Education, GREECE
}

Received 17 October 2019 • Revised 12 December 2019 • Accepted 20 December 2019

\begin{abstract}
Recognition of diversity and special educational needs within the contemporary educational system is regarded as a significant practice which promotes accessibility and full participation for all. The purpose of this study is: (a) to propound all the important parameters related with coeducation between typically and non-typically developed children within the elementary school, and (b) to infer useful conclusions concerning the attitude, knowledge, and capability of Greek elementary school teachers regarding inclusive co-education. In the current study, the aspects of 303 teachers from the Epirus Region, Greece, were analyzed on issues concerning co-inclusive education and educators' retraining. The educators state that they are due for support in order to correspond to all students' needs in the general school. They correlate co-inclusive education with the retraining of the educators as well as with the collaboration between all members of the faculty.
\end{abstract}

Keywords: co-education, teachers, elementary school, retraining.

\section{Introduction}

On a European level there is a constantly rising need for acknowledging co-education as a means of fighting against racism, discrimination, of promoting the status of being a citizen and the acceptance of different views, beliefs and ways of life. Co-inclusive education, viewed as a reform that fully corresponds to the students' diversity, takes under account that general schools which have an inclusive orientation are the most effective means towards accomplishing "education for all". Elementary school teachers must comprehend that diversity is just a natural aspect of human development and that they should be capable of teaching all children through cooperative forms of work, predicated on multi-leveled processes (Forgács, 2012; Rieser, 2013). It is crucial that teachers are fully aware of the special educational needs, legislation and teaching strategies, possess skills of interpersonal communication and know how curricula are formed (Forlin, 2012; Jordan, Glenn \& McGhie-Richmond, 2010). Teachers do need a cognitive basis along with technical and practical qualifications. On implementing an inclusion-free education it is essential that they acquire capabilities such as articulate communication towards all their students, being able of regulating high expectations, making time for small groups tutoring as well as for individualized intervention and also providing time towards those students who are most in need of (Forlin, 2012; Jordan, Glenn \& McGhie-Richmond, 2010).

(C) Authors. Terms and conditions of Creative Commons Attribution 4.0 International (CC BY 4.0) apply. Correspondence: Panagiota Strati (PhD), University of Ioannina, Department of Pre-School Education, GREECE. E-mail: panagiotastrati@yahoo.gr. 
M. Sakellariou, P. Strati \& P. Mitsi - Aspects of Greek Teachers Concerning Teaching Within ...

- The key factor is the endorsement by a parallel support educator successful co-education.

- All the educators who took part in our study agree that a modified curriculum aiming at coinclusion must take on account components of the social domain.

- All the educators either agree or strongly agree that children with special educational needs or disability should participate in activities in which their peers are involved as well.

- Retraining of the educators is a vital stage of the actualization of co-educational practices.

On the bibliographical review (EADSNE, 2010) the basic approaches towards dealing with challenges on the section of the educators' training are underlined and the extensive practical experience along with a parallel teaching of courses relevant to the issues is reported, as well as the acquisition of strategies in order to aid the students and handle their own beliefs and admissions related to learning and students. It is vital that teachers gain awareness about the experiences of people who are different from them, obtain methods such as case study. In addition to the above, teachers must hold the role of a researcher as well as an evaluator of their students' performance with the use of personal portfolios and, of course, must implement learning on reallife problems during their internship.

The educators must be taught of how slight changes ought to be made in order for the co-inclusion to be furthered. Our goal should be children to participate into the general class activities, after the application of minor changes or with some extra help. Such an objective could be accomplished by the use of a variety of methods with regards to the activities as well as by making adjustments with the help of visual footage or/and a question that is customized to children with special cognitive needs or disability. If such a modification does not suffice, then School can offer additional activities so that a child's special difficulties are subdued and, most certainly, collaborate with the family in order assistance to be provided at home (Holdsworth, 2000).

Multi-leveled processes allow educators to plan and adapt their teaching on the purpose of all students being able to keep up (Perner \& Porter, 2008; Strati, 2017). Multi-leveled teaching includes a four-step planning process:

(1) Concept that is to be taught;

(2) Methods that are utilized in order to assist students comprehend in their own pace;

(3) Way of presenting new information towards students; and

(4) How students comprehend and demonstrate what they have learned.

One of the key factors that contribute to the success of co-education between children of typical and non-typical development is the existence of a positive attitude on behalf of both, teachers and students towards kids with special educational needs and towards co-education itself (Paschidou, 2011; Sakellariou, Strati \& Anagnostopoulou, 2015). During their studies years (UNESCO, 2009) educators should be offered the opportunity to evolve basic skills which shall allow them to be able to teach all children. These skills include:

- Planning and teaching on co-education as well as access to the curriculum;

- Behavioral management along with realization of emotional and psychological needs of the students (building of their self-esteem as tutees);

- Cognitive evaluation (learning capabilities);

- Comprehension of when professional advice is necessary and wherein can such advice be sought.

Elementary school teachers should utilize various educational methods which have proven to be effective on students of special educational needs, such as: cooperative teaching, teaching through peers, supportive class environment, social skills, awareness of teaching strategies, self-regulative learning, memory strategies, phonological awareness and processing, 
behavioral approaches, functional behavioral assessment, direct instruction, evaluation and practice, formative assessment and feedback, support by technological assets, auxiliary and alternative forms of communication (Mitchell, 2008). Most of the above techniques have, indeed, proven to be methods effective towards all students thus they should be taught to the educators.

After all, within the Greek Education System as well, the necessity for a more comprehensive orientation emerges, as this is stated in the UNESCO's Advocacy Guide (2013), where it is clearly remarked that: "Training teachers towards an exclusion-free education means that we revise their roles, attitude and qualification so that they are prepared for the diversification of their teaching methods, re-determine the relationship between teachers and students and fortify teachers as co- creators of the curriculum".

\section{Methodology}

\subsection{Research sample}

For the current research, the aspects of 303 elementary school teachers from the Region of Epirus, Greece, were investigated, concerning issues of co-inclusive education as well as issues on the educators' further training. The participants were asked to prioritize the factors that affect co-education, locate evidence necessary to a modified curriculum which aims at coeducation, and evaluate on views that demonstrate the attitude of educators towards inclusive education.

\subsection{Demographics of the educators constituting the research population}

From a total of $\mathrm{N}=303$ educators, the majority of the respondents (55.0\%) were of female gender while $45.0 \%$ were males, as shown on Figure 1, below.

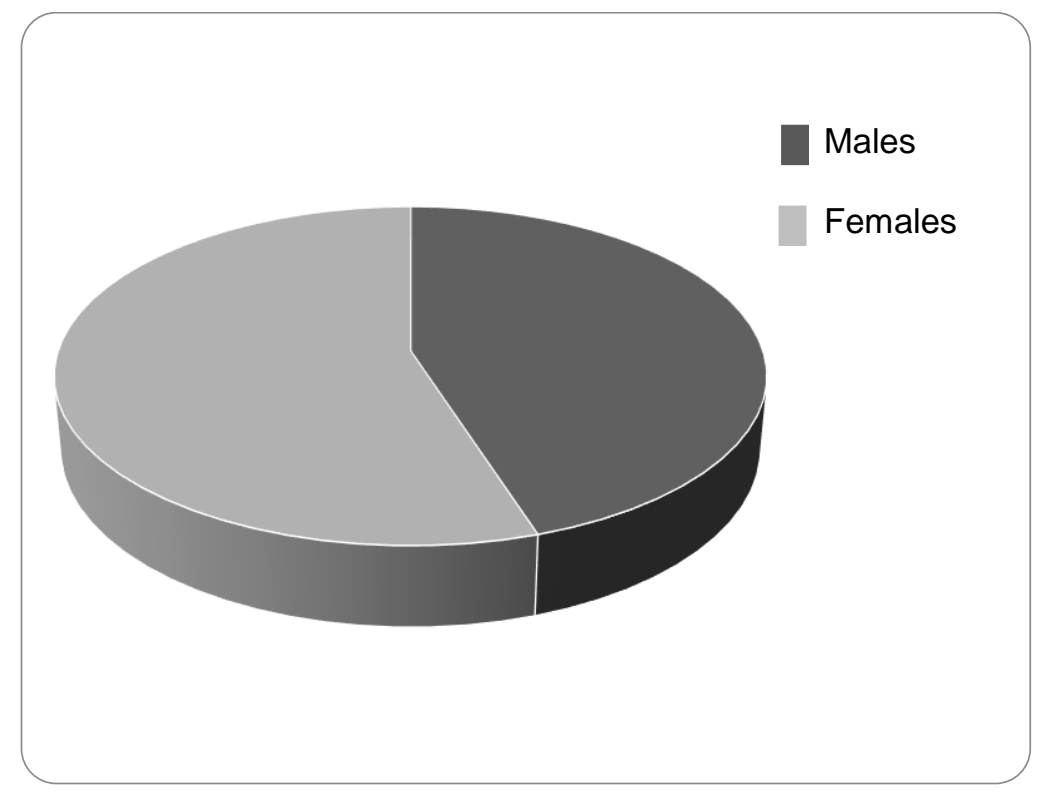

Figure 1. Gender of educators

Regarding their years of educational experience $40.6 \%$ range from 11 to 20 years, a $21.8 \%$ have 21 to 30 years of work experience, $20.0 \%$ between 6 and 10 years, $13.0 \%$ up to 5 years, while a shorter amount, $4.6 \%$ that is, of the educators have a work experience that exceeds 30 years (Figure 2). 


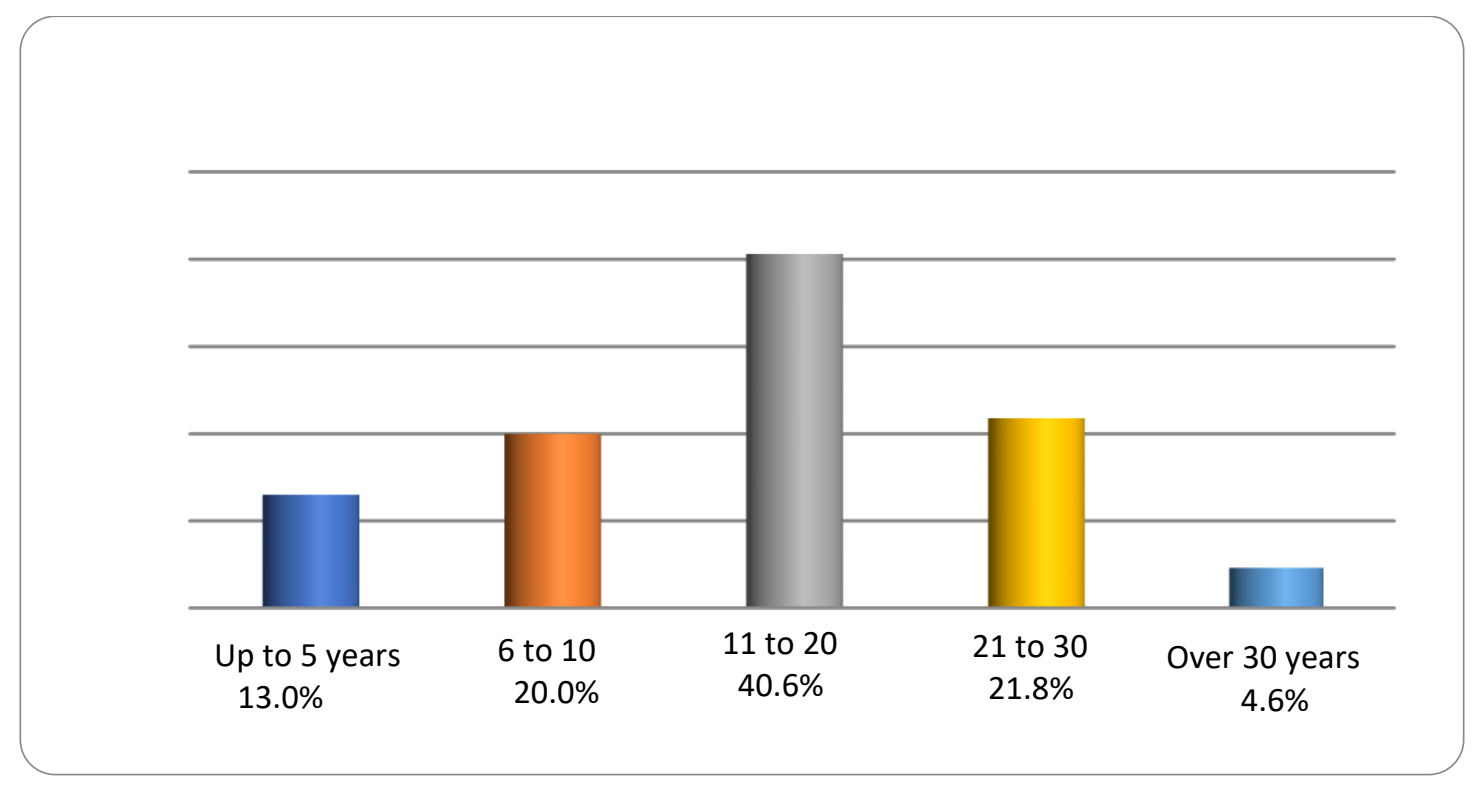

Figure 2. Years of working experience

The highest percentage (48.5\%) of the sample respondents possess no other degree than that which has been obtained from their basic university studies. A 16.5\% have undertaken a further training course on a teaching center, and $11.0 \%$ have attended an academic and professional upgrade program. An $\mathbf{1 1 . 5 \%}$ possess an additional University / Technological Educational Institution (TEI) degree, 8.5\% have a PGCE (Post Graduate Certificate in Education), $2.3 \%$ possess a PhD while a small amount (1.3\%) have attended the School of Pedagogical and Technological Education (A.S.PE.T.E.).

Of the $\mathrm{N}=303$ teachers who took part in our research, the highest percentage $53.0 \%$, have only limited awareness about children of special educational needs and disability, $17 \%$ good awareness, $16 \%$ adequate awareness, $14 \%$ no awareness and $0 \%$, none of the teachers that is, would evaluate their awareness to be of optimal level (Figure 3).

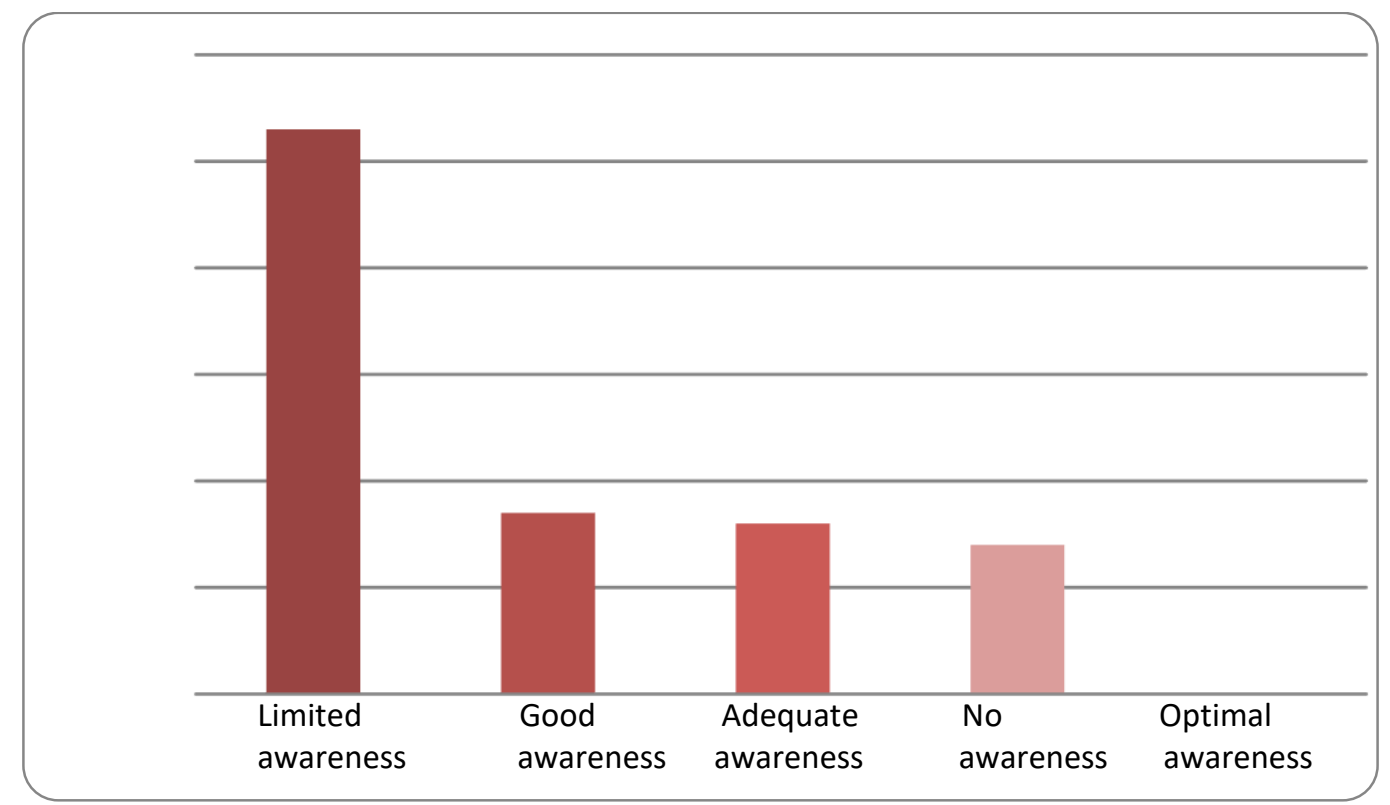

Figure 3. Distribution of educators regarding their level of awareness on special education 


\subsection{Purpose of the research}

The purpose of our study is to formulate the crucial parameters that relate to coeducation of typically and non-typically developed children as well as to infer useful conclusions about the attitudes, awareness and skills of the elementary school education teachers concerning co-inclusive education.

\subsection{Hypotheses of the research}

We hypothesized that:

(1) A significant factor to a successful co-education for teachers is the teaching style itself.

(2) They concur that a modified curriculum aiming at co-inclusion shall take on account ways of linguistic, social abilities and role-play development.

(3) They do believe that educating children of special needs and disability within the general class could possibly disturb the educating of typically developed students.

(4) They deem that they lack the expertise to teach students of disability or special educational needs. They feel insufficient of living up to a coeducational curriculum.

\subsection{Investigational tool}

Survey research via questionnaire was considered as the most appropriate method of collecting data with regards to recording of aspects by a representative sample of elementary school educators on issues of co-education of children who present special educational needs or/and disability within the general class. After a scrutiny on the relevant literature, a questionnaire based on "open-ended" and "close-ended" inquiries, was formed.

3. Presentation of the study results

\subsection{Co-educational factors}

Regarding your hitherto education and practical experience, please note down the factors that affect co-education of typically and non- typically developed children by a descending order of importance 1-6, starting from 1 as being the most significant and 6 the less significant one.

After analyzing the data we conclude that teachers opt for pastoral help by the parallel support educator (Mean 2.52) as being the factor of uttermost importance, followed by the modification of the curriculum (Mean 3.16), the teacher's ability of dealing with behavioral issues (Mean 3.23) social integration with peers (Mean 3.74), class environment (Mean 3.89) and, lastly, in terms of importance concerning teachers, comes the factor of teaching style (Mean 4.38). 
M. Sakellariou, P. Strati \& P. Mitsi - Aspects of Greek Teachers Concerning Teaching Within ...

Table 1. Prioritizing of options concerning factors of a successful co-education

\begin{tabular}{|l|c|c|c|c|}
\hline \multicolumn{1}{|c|}{ Co-educational factors } & $\mathrm{N}$ & Mean & Std. Deviation & Std. Error Mean \\
\hline Teaching style & 303 & 4.38 & 1.457 & .084 \\
\hline Class environment & 303 & 3.89 & 1.751 & .101 \\
\hline $\begin{array}{l}\text { Modification of } \\
\text { curriculum }\end{array}$ & 303 & 3.16 & 1.658 & .095 \\
\hline $\begin{array}{l}\text { Ability of teacher to handle } \\
\text { behavioral issues }\end{array}$ & 303 & 3.23 & 1.302 & .075 \\
\hline $\begin{array}{l}\text { Social integration of } \\
\text { children with special } \\
\text { needs among their peers }\end{array}$ & 303 & 3.74 & 1.544 & .089 \\
\hline $\begin{array}{l}\text { Backing of class by a parallel } \\
\text { support educator }\end{array}$ & 303 & 2.52 & 1.841 & .106 \\
\hline
\end{tabular}

On assessing the variant concerning gender, a statistically significant difference is located only on the question regarding the backing of class by a parallel support educator, on which such a practice is prioritized as more important by female teachers in comparison to their male colleagues $(\mathrm{p}<0,001)$. This differentiation is clearly demonstrated on the following Figure (Figure 4).

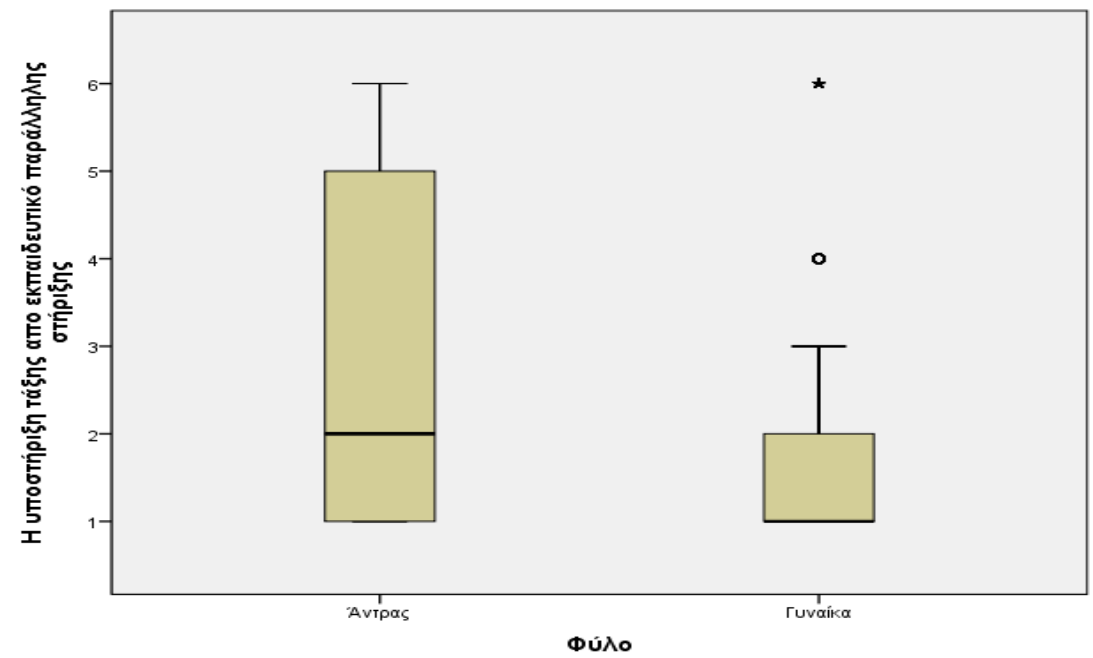

Figure 4. Distribution of the two groups (males/females) respectively to the educators' views on the factors that lead to a successful integration

\subsection{Modified curriculum on the purpose of co-inclusion}

At what degree is it significant for the following components to be encompassed within a modified curriculum on the purpose of co-inclusion?

- Gain awareness on elements of the environment;

- Evolve the ability of imitating others;

- Development of language use and comprehension;

- Be taught of the appropriate role by playing games and by using objects;

- Improvement of social skills through interaction. 
To gain awareness on elements of the social environment thus being a component that must be encompassed within a curriculum which is orientated towards all children, is considered as highly significant by $5 \mathbf{1 . 2} \%$ of the teachers, significant for a $45.9 \%$ and less significant for $3.0 \%$ of them. The ability of imitating others seems to engender quite different views among teachers, though. More specifically, such a component is regarded as highly significant for $19.5 \%$ of them, significant for a $45.2 \%$, less significant for $30.4 \%$ of them, whereas a $5.0 \%$ consider it to be insignificant whatsoever.

Developing skills of linguistic use and comprehension for children of special educational needs so that they can have a more regular integration within the school context is a crucial element of a curriculum which is orientated towards co-inclusion. More specifically, it was deemed to be very significant by $64.0 \%$ of the teachers and significant for $36.0 \%$ of them. To gain awareness of the appropriate role concerning playing and object utilization is a part of the curriculum on which, in terms of significance levels, teachers agree by: $63.7 \%$ as being very significant, $43.7 \%$ significant and a mere $2.3 \%$ consider it as slightly significant. Amelioration of social abilities through interaction must be a goal to every curriculum, even more so when one takes on account of how vital social abilities are for individuals of special educational needs. High is the amount of teachers who regard this element as very important; $75.9 \%$ that is.

\subsection{Aspects of the educators regarding integrative education}

Please, evaluate the following views which reflect the attitude of educators towards integrative education, on a scale 1-5 where: Strongly agree.

1: Strongly disagree/ 2: Disagree/ 3: Neither disagree nor agree/ 4: Agree/ 5:

\subsection{Professional training of the Greek teachers}

Studying of the views of educators whether or not they possess the professional training suitable for teaching students with disability in the general class, we deemed as necessary that we should evaluate such a question in terms of the variable concerning the awareness of educators towards integrative education (Figure 5). The educators that do have an adequate awareness of disabled children differ the most as to possessing professional training on coeducation (Mean 2.23). However, all the educators that have only limited awareness (Mean 2.33) on co-education also disagree, as well as those who have no awareness (Mean 2.37) and good awareness (Mean 2.59). 


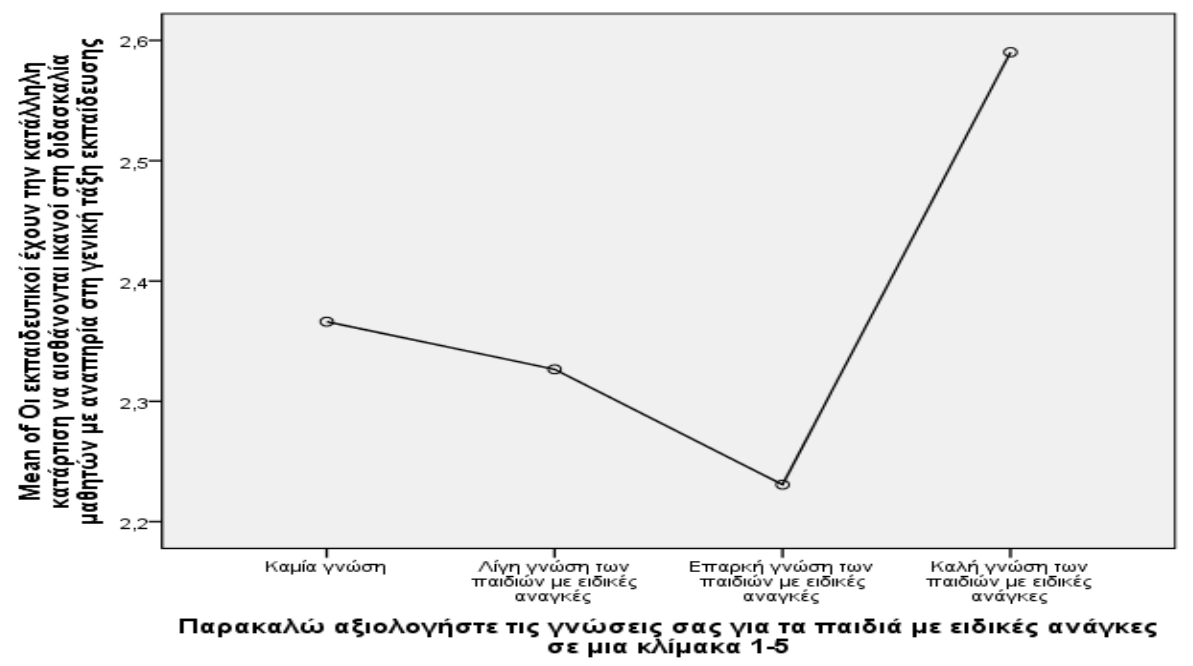

Figure 5. Distribution of groups regarding the level of special education teachers' awareness on the educators' professional training

\subsection{Awareness, skills and experience of teachers concerning co-education}

Educators who have no awareness on children with special educational needs strongly disagree (Mean 1.89), those who possess limited awareness (Mean 2.18) and adequate awareness (Mean 2.14) simply disagree, while the respondents who possess a good awareness on children with special educational needs (Mean 2.34) neither agree nor disagree on whether teachers have the awareness, skills and experience to be teaching students with disability within their class (Figure 6). According to the ANOVA Analysis of Variance a significant statistical difference occurs among the educators' responses $\mathrm{F} 3 \cdot 516=3.603, \mathrm{P}=0.013$.

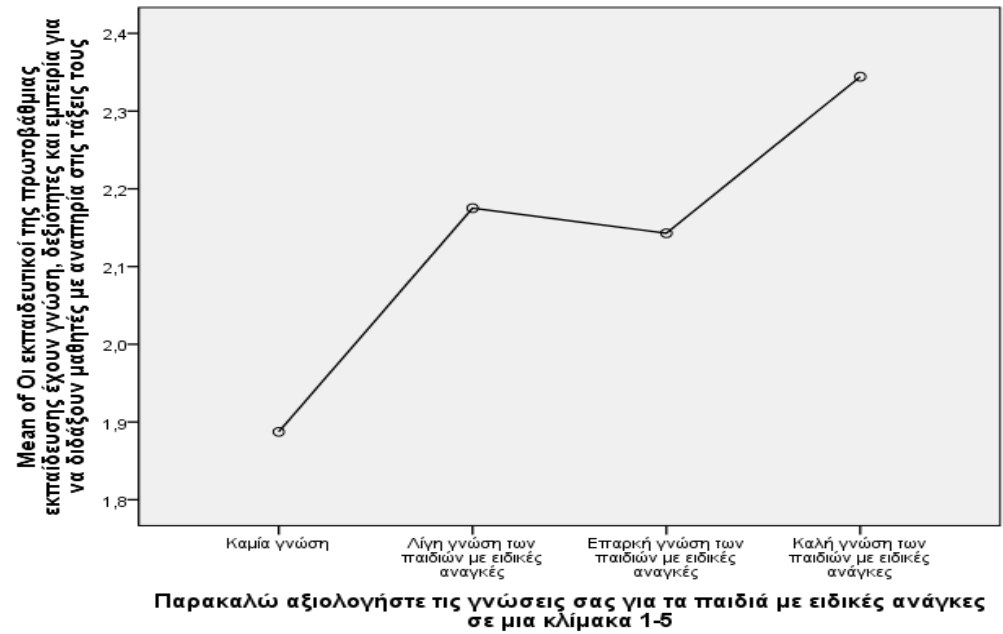

Figure 6. Distribution of groups regarding the level of special education teachers' awareness on the educators' awareness, skills and experience

Are all educators equipped with the support necessary to meet the requirements of students with special educational needs not only inside but outside the School, as well? 
A $41.6 \%$ of the teachers disagree and $44.6 \%$ strongly disagree that all educators are provided with the support necessary to satisfy their disabled students' needs.

\subsection{Co-education of typically and non-typically developed children}

Examining the variant (Figure 7) concerning the level of awareness among the educators on issues of disability, as well as their aspects on co-education and whether it disturbs the educating of typically developed children, one can see that Teachers who possess a good awareness $(\mathrm{N}=61$, Mean 2.31) and adequate awareness $(\mathrm{N}=91$, Mean 2.30), disagree on any impediments being caused on typically developed children by being taught in the same class as their disabled peers, whereas educators who possess limited awareness ( $\mathrm{N}=297$, Mean 2.88) and no awareness ( $\mathrm{N}=71$, Mean 3.14) neither agree nor disagree. According to the ANOVA Analysis of Variance, a significant statistical difference occurs among the responses of the educators $\mathrm{F}^{3 \cdot 516}=$ 9.371, $\mathrm{P}=0.000$.

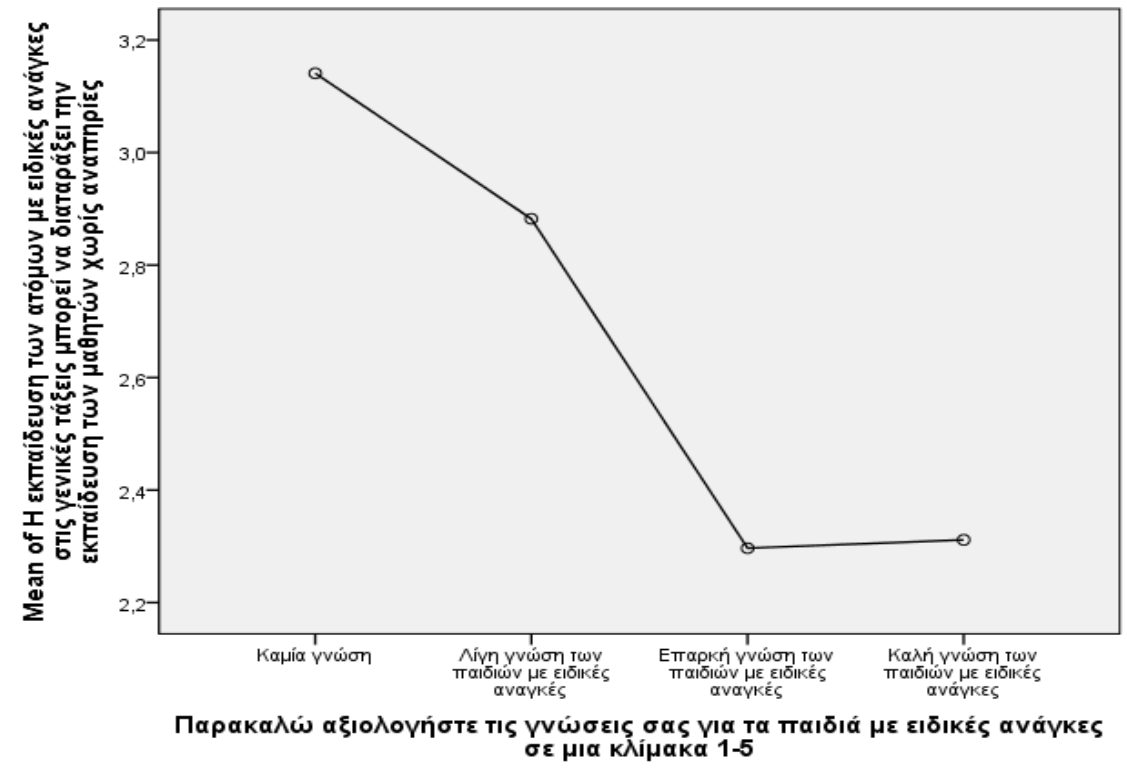

Figure 7. Distribution of groups regarding the level of special education teachers' awareness on co-education of typically along with non-typically developed students

Should students with special educational needs or/and disability participate in class activities with their peers?

All the educators either agree or strongly agree on children with disability and special educational needs participating in activities along with their classmates; $41.9 \%$ agree and $39.6 \%$ strongly agree. Small is the percentage of neutral opinions, anyway.

Do non-disabled students acquiesce at their classmates with disability or special educational needs sharing the same class with them?

The teachers, by a percentage of 35.6\% neither agree nor disagree - they differ on the view that non-disabled students accept their peers with special educational needs or disability within the general class.

\subsection{Diminished academic achievement within co-educational classes}

The educators who possess a good awareness either disagree or even strongly disagree $(\mathrm{N}=61$, Mean 1.84) that general education classes which include students with special educational 
needs shall manifest diminished academic achievement (Figure 8). Educators of no awareness on children with special educational needs, waver - neither agree nor disagree that is (Mean 2.70). Those who possess limited awareness show a tendency towards disagreeing (Mean 2.32), while the educators who possess adequate awareness disagree (Mean 2.09). According to the ANOVA Analysis of Variables, a significant statistical difference occurs among the educators' responses; $\mathrm{F}^{3} \cdot 516=9.731, \mathrm{P}=0.0$.

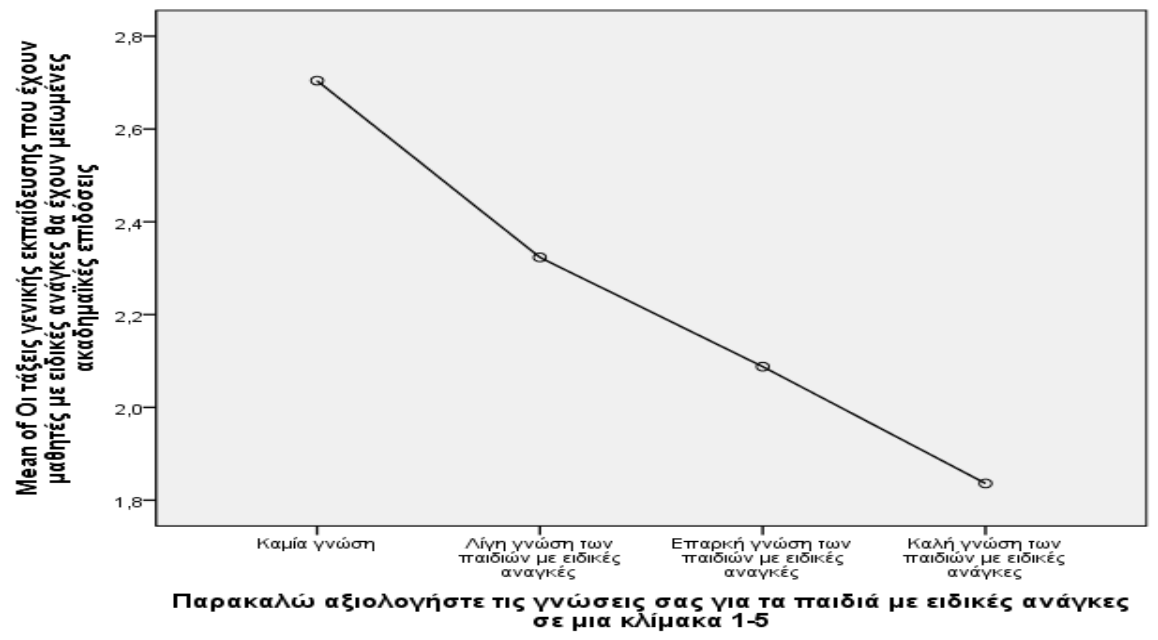

Figure 8. Distribution of groups regarding the level of special education teachers' awareness on co-educational classes in terms of academic achievement

\section{Concluding discussion}

After the analysis of data regarding the factors to a successful co-education we establish that as far as the teachers who participated in the current study are concerned, the key factor is the endorsement by a parallel support educator, then comes the modification of the curriculum and the teachers' ability of dealing with behavioral issues. Our first hypothesis that for teachers teaching style holds a significant role towards a successful integration within the general class, fails to be certified, since such a factor is placed at the bottom of their evaluation.

With the dissemination of the constitution of parallel support, children with severe disabilities are now given the opportunity to attend the general class curriculum and be substantially endorsed (Sakellariou, Strati \& Anagnostopoulou, 2019; Strati, 2018). However, a series of arguments occurs due to the increasing number of educators who provide specialized educational support and hold an expanded role in the context of the general class. Are duties and roles which they shall hold, the suitable ones? Are educators, indeed, fully knowledgeable of such roles? Are those who actually help children with special educational needs to be integrated within the general class? How can the educators prove themselves to be effective on their tasks? These questions are of major significance when it comes to appropriately supporting students with special educational needs or disability within general educational settings.

All the educators who took part in our study agree that a modified curriculum aiming at co-inclusion must take on account components of the social domain, the ability of imitating others, the development and comprehension of language, role-play and objects utilization. Improving of social abilities via interaction must be a high purpose to every curriculum. This is, in fact, a point on which our initial hypothesis is confirmed.

All the educators either agree or strongly agree that children with special educational needs or disability should participate in activities in which their peers are involved as well. This is 
not the case, though, for the educators who possess no awareness on special education; they seem to waver. We regarded that the more one is knowledgeable on special education, the closer their responses come to the "strongly agree" column.

The educators clearly state that they call for support in order to be able to meet all their students' needs in the general school. Retraining of the educators is a vital stage of the actualization of co-educational practices. Retraining on integration issues must be multi-leveled and well defined. While most educators seem to opt for the general principles of co-education, there is a wide field of disagreement as of its interpretation as well as its implementation. Emphasis should be given on the quality of teaching that the students are provided with, but also on the educational outcome upon them.

A useful context regarding the collection of data about the overall practice of the educators should be offered, which is called “Inclusive Pedagogical Approach in Action". This work is actually an attempt towards the conceptualization of an exclusion-free pedagogical process. It is based on a whole of theoretical principles that can support educators, adult educators' trainers and researchers so that they become capable of reaching decisions appropriate for pedagogics on every single domain (Florian, 2012; Spratt \& Florian, 2014).

From the results analysis the need of a continuous approach is underlined; an approach in the context of which, the initial training of teachers is in absolute alignment with the transition to professional teaching and the constant occupational evolution, we thus suggest that:

- An explicit reference framework is established, common ground is provided among the various regulations of teaching and cognition, the different stages (initial training, transition to the occupational position as well as constant professional evolution), activities and operators.

- Consistency on the evaluation of the educators and feedback upon the fundamental formats and procedures determining what, how, why and when evaluation is apt and also by whom is it to be conducted.

- Thorough selection, preparation, professional evolution and support of the adult educators' trainers in order for them to be able to provide conditions appropriate for the development of the educators potentiality not only at school but at the university as well.

- A common policy framework with regards to an efficient school leadership, towards insuring of principals of quality schools, who are capable of observing and supporting the incentives and practices of the educators in terms of ameliorating teaching and cognition (European Commission, 2014).

A well-defined practice on an exclusion-free education (Boyle, Scriven, Durning \& Downes, 2011; Opertti \& Brady, 2011), is not always clearly delineated, it frequently, nonetheless, determines the success or failure of the environmental, teaching, educational factors, as well as that of social integration (Forlin, Chambers, Loreman, Deppeler \& Sharma, 2013). Specific practices do exist, however, which can work as a whole of principles that could be utilized towards guiding the educators and the overall policy, on a clear determination regarding co-education.

\section{Conclusion}

A successful integration on co-inclusive schools must take on account comprehension and acknowledgement of integration as a continuous and ever-evolving process (Winter \& O'Raw, 2010). Cognitive habitats should be formed, which truly correspond to all students' needs, accomplishing this way, social, emotional, physical and mental development. Appropriate curricula should be designed by the universities, which would be customized to fit all students' 
needs. The participation of students, educators, families and parents as members of the community within the school projects, should be enhanced and preserved.

It is of general concurrence that the cognition of the educators should not be only restricted within their initial studies, but to be expanded throughout their career. Educating, in terms of a lifetime career process means that such cognitive forms via occupational continuity can be developed through the whole teaching time. School practice is a way of strengthening coeducation, learning, that is, from active educators as well as from other members of the faculty. It is of common awareness that from the teaching practices and attitudes that educators are taught in the university, they adopt those which dominate the school environment (McIntyre, 2009). There is a rich variety concerning relations that occur from practice at school (McMahon, Forde \& Dickson, 2015). The newly mapped-out elements reveal a clear tendency towards increasing the amount of practical training, including the school practices, within the context of contemporary curricula (European Commission, 2015).

Educational reformations by the Ministry of Education should be actualized, which would focus on pinpointing and reducing barriers on cognition and participation. It is necessary that policies and practices within schools are restructured so as to take culture under account, in order for them to manage to correspond towards the diversity of students in each region. Within the general reforming, suitable training and professional evolution of the whole school faculty should be included. We emphasize on the need of ensuring of information related to policies and practices, information that is accessible to everyone without exclusion: students, parents, support staff and generally, all individuals who are involved in kids' education, so to say.

Conclusively, the current study aims at investigating on significant parameters that relate to co-education between typically and non-typically developed children and extracting useful conclusions on aspects, awareness and skills of teachers concerning co-inclusive education. It is deemed necessary, though, that further research should be conducted at more Greek Regions so that a higher generalization of results is possible. Interventional curricula should be implemented within elementary school classes in order for co-education to take the shape of a uniform education (one educational framework for all students).

Author Contributions: Writing-Review \& Editing, M.S, P.S, P.M.; Supervision, M.S; Validation, M.S, P.S, P.M.; Introduction, M.S, P.S, P.M.; Methodology, M.S, P.S, P.M.; Results, M.S, P.S, P.M.; Discussion and Conclusions, M.S, P.S, P.M.;

\section{Acknowledgements}

This research did not receive any specific grant from funding agencies in the public commercial, or not-for-profit sectors.

The authors declare no competing interests. 


\section{References}

Boyle, C., Scriven, B., Durning, S., \& Downes, C. (2011). Facilitating the learning of all students: The 'professional positive' of inclusive practice in Australian primary schools. Support for Learning, 26(2), 72-78.

EADSNE (2010). Teacher education for inclusion: International literature review. Odense: European Agency for Development in Special Needs.

European Commission (2014). Initial teacher education in Europe: An overview of policy issues. Brussels: European Commission.

European Commission (2015). Strengthening teaching in Europe. New evidence from teachers compiled by Eurydice and CRELL, June 2015. Brussels: European Commission.

Florian, L. (2012). Preparing teachers to work in inclusive classrooms: Key lessons for the professional development of teacher educators from Scotland's inclusive practice Project. Journal of Teacher Education, 63(4), 275-285.

Forgacs, R. T. (2012). Strengthening teacher education to achieve EFA by 2015: How are student teachers prepared to adopt inclusive attitudes and practices when they start teaching? Consultancy report, UNESCO.

Forlin, C. (2010). Teacher education for inclusion: Changing paradigms and innovative approaches. Oxford: Routledge.

Forlin, C. (2012). Diversity and its challenges for teachers. In: C. Forlin (Ed.), Future directions for inclusive education (pp. 83-92). London: Routledge.

Forlin, C., Chambers, D., Loreman, T., Deppeler, J., \& Sharma, U. (2013). Inclusive education for students with disability. A review of the best evidence in relation to theory and practice. The Australian Research Alliance for Children and Youth (ARACY).

Holdsworth, J. C. (2000). Learning 'How' and learning 'Why' - Watching teachers in Asia move towards more inclusive styles of work. Retrieved, 10 November 2018, from http://www.isec2000.orq.uk/abstracts/papers h/holdswoth 1.html.

Jordan, A., Glenn, C., \& McGhie-Richmond, D. (2010). The supporting effective teaching (SET) project: The relationship of inclusive teaching practices to teacher beliefs about disability and ability, and about their roles as teachers. Teaching and Teacher Education, 26, 259-66.

McIntyre, D., (2009). The difficulties of inclusive pedagogy for initial teacher education and some thoughts on the way forward. Teaching and Teacher Education, 25(4), 602-608.

McMahon, M., Forde, C., \& Dickson, B. (2015). Reshaping teacher education through the professional continuum, Educational Review, 67(2), 158-178.

Mitchell, D. (2008). What really works in special and inclusive education: Using evidence based teaching strategies. London: Routledge.

Opertti, R., \& Brady, J. (2011). Developing inclusive teachers from an inclusive curricular perspective. Prospects, 41, 459-472.

Patsidou- Eliadou, M. (2011). Perspective of co-education in secondary education; aspects of educators and pupils. An interdisciplinary approach. Innovation on Education. Kyriakides bros.

Perner, D., \& Porter, G. (2008). Creating inclusive schools: Changing roles and strategies. PowerPoint from Research Based Practices in Developmental Disabilities.

Rieser, R. (2013). Teacher education for children with disabilities literature review. For UNICEF REAP Project. 
Sakellariou, M., Strati, P. \& Anagnostopoulou, R. (2019). The role of parallel support educators within preschool Education. Proceedings of the $2^{\text {nd }}$ International Symposium on Pre-school Pedagogics Transformative Pedagogics and Learning in Childhood. Ioannina: University of Ioannina. PEDIO Publications

Spratt, J., \& Florian, L. (2014). Developing and using a framework for gauging the use of inclusive pedagogy by new and experienced teachers. In: C. Forlin, \& T. Loreman (Eds.), Measuring inclusive education (international perspectives on inclusive education), 3. Bingley: Emerald Group Publishing Limited.

Strati, P. (2017). Inclusion of typically and non-typically developed children inside the general class and their transition from the Kindergarten to the Elementary School. Doctoral Thesis, University of Ioannina.

Strati, P. (2018). La transizione dei bambini con bisogni speciali dalla Scuola Materna alla scuola elementare. Il ruolo del sostegno nel loro inserimento. DIADRASI Publications, ISBN: 978618-5059-97-2

UNESCO (2009). Policy guidelines on inclusion in education. Paris: UNESCO.

UNESCO (2013). Advocacy guide: Promoting inclusive teacher education - Introduction. Bangkok: UNESCO.

Winter, E., \& O'Raw, P. (2010). Literature review of the principles and practices relating to inclusive education for children with special educational needs. Trim, Ireland: National Council for Special Education. 